\title{
Establishment and characterization of a Holstein cow mammary epithelial cell line
}

\author{
Y.Y. Ding, L.L. Zhang, Y.J. Huo, S.S. Chen and T. Wang ${ }^{1}$ \\ College of Animal Science and Technology, Nanjing Agricultural University \\ 210095 Nanjing, P.R. China
}

\begin{abstract}
The study was carried out to establish in vitro a cow mammary epithelial cell (MEC) line, able to respond to lactogenic hormones and rat tail collagen gel. Different from others' way of harvesting MEC from digested tissue filtrate, tissue plants culture was used uniquely. Cells grew out from plants which were plated on collagen-coated plastics, at confluency, exhibited the characteristic cobblestone morphology of epithelial cells. All cells stained strongly for cytokeratin 18 but not with vimentin. Detectable quantities of $\alpha$-casein and $\beta$-casein were present in the differentiation media. This study noted the establishment of a functional cow MEC line.
\end{abstract}

KEY WORDS: mammary, epithelial cell, cells morphology, cytokeratin 18, casein

\section{INTRODUCTION}

Milk synthesis occurs within clusters of differentiated mammary epithelial cell (MEC) and is controlled by lactogenic hormones and extracellular matrix interactions (Akers, 1991). Accurate replication in vitro of bovine mammary gland function is of great importance to studies on the control of milk synthesis and secretion.

Several MEC lines also existed, included the BMEC+H line, PS-BME-7 line, and MAC-T line et al (Talhouk and Neiswander, 1990). However, the level of milk protein synthesis of these MEC lines is either very low or non-existent, and if it does occur, it is independent of some or all of the in vivo factors known to regulate lactogenesis. These cell lines are not suitable for investigations of mammary gland function.

Here our study establish a functional cow MEC line. Cell function is unaffected by cryopreservation and it is responsive to lactogenic hormones, and rat tail

\footnotetext{
${ }^{1}$ Corresponding author: e-mail: tianwang@njau.edu.cn
} 
collagen gel. The cell line is not immortal, and after about 35 passages of growth, the cells visibly senesce and are unable to replicate further.

\section{MATERIAL AND METHODS}

\section{Mammary tissue dissociation and cell culture}

Primary cow mammary gland tissues were obtained by aseptic biopsy from lactating Holstein cows at slaughter, then were washed with serum-free RPMI1640 and were minced into $1 \mathrm{~mm}^{3}$ slices. Then these slices were placed on RTCG (prepared according to Michalopoulos and Pitoe, 1975) coated plastic Petri dishes; cultures were maintained at $37^{\circ} \mathrm{C}$, in a $5 \% \mathrm{CO}_{2}$, and $100 \%$ humidity incubator; medium was RPMI-1640 supplemented with $15 \%$ newborn bovine serum, and $100 \mathrm{IU} / \mathrm{ml}$ penicillin, $100 \mathrm{ug} / \mathrm{ml}$ streptomycin, $5 \mu \mathrm{g} / \mathrm{ml}$ insulin, $1 \mu \mathrm{g} / \mathrm{ml}$ hydrocortisone. Culture fluids were changed every $3 \mathrm{~d}$ after cells grew out from plants, and cells were passaged at confluence. Fibroblasts and plants detached after a few minutes of treatment with TE $(0.25 \% 1: 250$ trypsin, $0.04 \%$ EDTA in PBS), leaving epithelial cells, which required at least $10 \mathrm{~min}$ to detach. They were microscopically visualized with an inverted microscope. In this way, MEC clones were established and were selected for further study.

\section{Grow assays}

Early passage MEC were plated at a density of $5 \times 10^{4}$ cells per well in a RTCGcoated 24-well plate. The number of cells per 3 wells was determined with a haemocytometer on each of $8 \mathrm{~d}$ after plating. The mean from 3 wells was used. Growth curves were constructed by plotting cell number versus the time in culture. Doubling time was determined by the slope during the log-phase.

\section{Karyotype}

The karyotype of the cells was determined every fifth passage from passage 5 to passage 20, using the method modified from that of Sun and Chu (1973).

\section{Immunofluorescence of cytoskeletal proteins}

Monoclaonal antibodies which react with cow cytokerain 18 and vimentin were used to characterize cell type as epithlelial or stromal; cells were seeded in 8-chamber slides, at confluency, and then fixed and stained according to manufacturer's recommendations. 


\section{Inducement of milk protein production}

MEC cells were suspended in medium supplemented additionally with $2 \mu \mathrm{g} / \mathrm{ml}$ prolactin, $10 \mathrm{ng} / \mathrm{ml} \beta$-oestradiol, and $10 \mathrm{ng} / \mathrm{ml}$ progesterone. Medium was replaced every other day and the culture was maintained for up to $16 \mathrm{~d}$. Spent medium was sotored at $-25^{\circ} \mathrm{C}$ for western blot analysis of $\alpha$-casein and $\beta$-casein.

\section{Statistical analyses}

Values were presented as the mean \pm SEM. Data were analysed using Student's test or analysis of variance, as noted in the text.

\section{RESULTS}

When plated on RTCG-coated plastic, the cells assumed a monolayer, cobblestone, epithelial-like morphology, with close contact between the cells (Figure 1a). When cells were cultured for extended periods of time and at high density, dome-like structures appeared (Figure 1b).
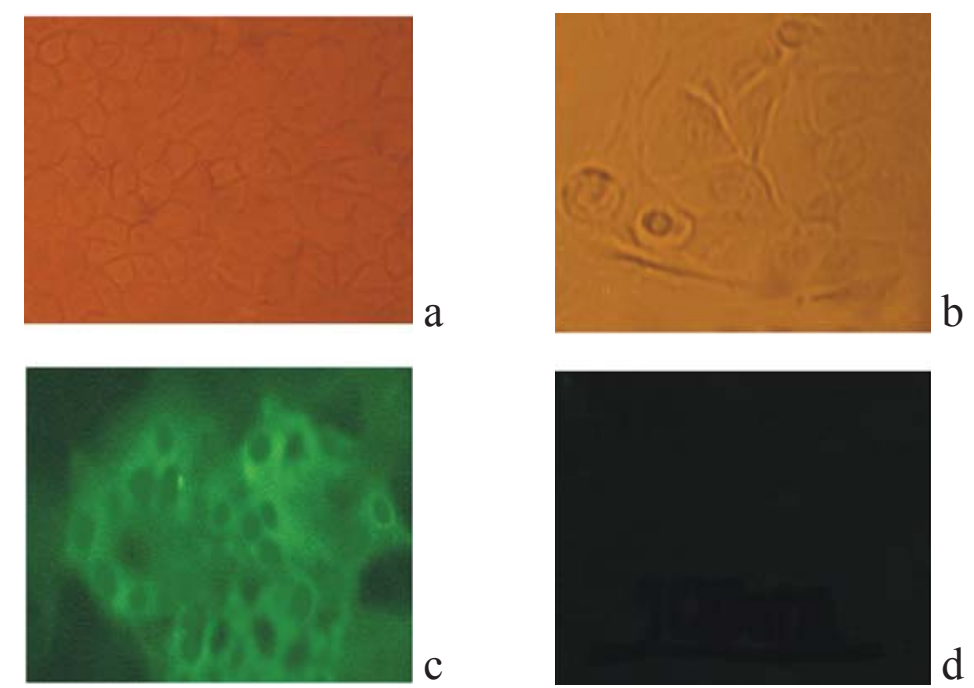

Figure 1. Cobblestone epithelial-like morphology of MEC at passage 5 (a) and dome-like structures of MEC at high density (b) and MEC stained for anti-cytokeratin 18 (c), stained for anti-vimentin (d). In all phase contrast photomicrographs, the magnification of the part (a) and (b) is $200 \times$, part (b) and part (d) is $400 \times$

At a NBS concentration of $15 \%$, the clone grew vigorously until it approached confluence, at about $5 \mathrm{~d}$ after passage (Figure 2). Doubling time was about $37 \mathrm{~h}$. 


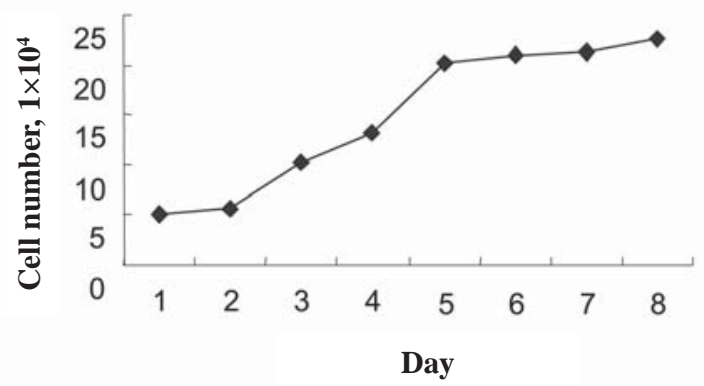

Figure 2. Growth curves of early passage MEC

Between passage 5 and 20 the model karyotype of the cells remained at 60 , the average values for passages $5,10,15$ and 20 were $59.8 \pm 1.24,59.2 \pm 1.57,59.8 \pm 1.43$ and $59.8 \pm 2.01$, respectively. By passage 30 and 35, the average karyotype were $57.1 \pm 2.25,56.7 \pm 1.24$, and the model values were 58 and 58 , respectively.

Confluent monolayers of the cells between passage 5 and 10 were stained for cytokeratin 18 (Figure 1c) and vimentin (Figure 1d). All cells were strongly stained for the cytokeratin 18 antibody, however, totally not apparent for vimentin.

Following electrophoresis under reducing conditions and subsequent blotting, the $\beta$-casein and $\alpha$-casein monoclonal antibodies recognized bands with molecular mass of $2.4 \mathrm{kDa}$ (Figure 3a, lane 2), $2.3 \mathrm{kDa}$ (Figure 3a, lane 2), respectively, in extracts of the lactogenic hormones treated cells. These two bands were never seen in spent medium of the control cells (Figure 3a, lane 3; Figure 3b, lane 3).
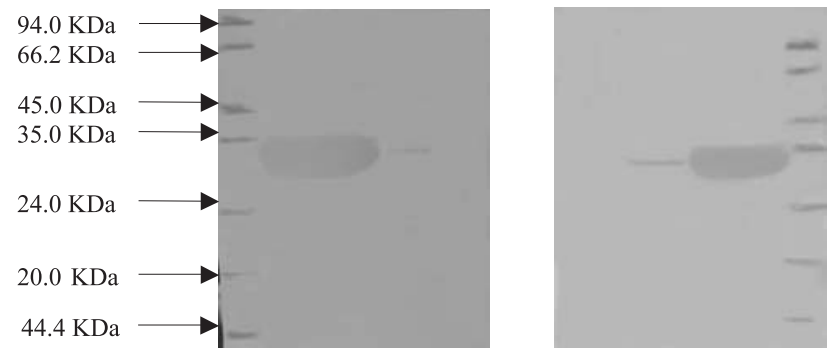

Figure 3. Detection of $\beta$-casein (a, lane 3 ) and $\alpha$-casein (b, lane 3) in MEC cell extracts by western blot analysis, lane 1 in (a) and (b) noted marker, lane 2 in (a) and (b) contained standard cow casein, lane 4 in (a) and (b) contained blank medium

\section{DISCUSSION}

This report detailed the establishment and characterization of a Holstein cow MEC line. The cells used in the present study exhibited some important functional and 
biochemical markers of the in vivo state. When growing on RTCG-coated plastic, the cobblestone morphology characteristic of epithelial cells were seen, as was a classical cytoplasmic network of cytokeratins, and responsiveness to the lactogenic hormones.

Rat tail collagen gel is an ideal extracellular matrix for bovine MEC, it contains principally laminin and collagen IV as well as a number of growth factors (Huynh and Robitaille, 1991). Others (Talhouk and Neiswander, 1990; Li et al., 1999) have suggested that collagen gel membrane allowed the cells to change shape and that there was a correlation between cell shape and the degree of differentiation. In this study, using collagen gels, the best results in terms of cell's formation of epithelial morphology and cells differentiation have been achieved.

Huynh and Robitaille (1991) have suggested that the geometry of the cells, their interaction with extracellular matrix constituents, cell-cell interactions, and maintenance of cellular polarity played a role in the expression of milk protein genes. Bovine mammary epithelial cells share a similar requirement for an extracellualr matrix and lactogenic hormones for maximum casein synthesis (Talhouk and Neiswander, 1990). In our study, when given appropriate stimulation, the cells produced $\alpha$-casein and $\beta$-casein, classical protein products of mammary epithelial cells. A fully robust indicator of cellular differentiation might also have included the expression of $\alpha$-lactalbumin and $\beta$-lactoglobulin (Li et al., 1999). Unfortunately, we didn't attempt to make MoAb to these bovine whey proteins. Further researches based on the results of this study will be done.

\section{CONCLUSIONS}

Our study found a way of establishing a functional bovine mammary epithelial cell line, which is responsive to lactogenic hormones and an extracellular matrix. Notwithstanding the deficiencies of the culture system, this cell line has application to the investigation of bovine lactation in vitro.

\section{REFERENCES}

Akers R.M., 1990. Lactation physiology: a ruminant animal perspective. Protoplasma 159, 96-111

Huynh H.T., Robitaille G., 1991. Establishment of bovine mammary epithelial cell lines (MAC-T): an in vitro model for bovine lactation. Exp. Cell Res. 197, 191-198

Li P., Wilde C.J., Finch L.M., Fernig D.G., 1999. Identification of cell types in the developing goat mammary gland. J. Histochem. 31, 379-393

Michalopoulos G., Pitoe H.C., 1975. Primary culture of parenchymal liver cells on collagen membranes. Exp. Cell Res. 94, 70-78

Sun N.C., Chu E.H.Y., 1973. Staining method for the banding patterns of human mitotic chromosomes. Mammal. Chrom. News Lett. 14, 26

Talhouk R.S., Neiswander R.L., 1990. In vitro culture of cryopreserved bovine mammary cells on collagen gels: synthesis and secretion of casein and lactoferrin. Tissue Cell 22, 583-599 